Research Article

\title{
Healthcare workers' structured daily reflection on patient safety, workload and work environment in intensive care. A descriptive retrospective study
}

\author{
Ing-Marie Larsson ${ }^{\mathrm{a}, \mathrm{b}, *}$, Anna Aronsson ${ }^{\mathrm{a}, \mathrm{b}}$, Karin Norén ${ }^{\mathrm{b}}$, Ewa Wallin ${ }^{\mathrm{a}, \mathrm{b}}$ \\ a Department of Surgical Sciences, Anaesthesiology E Intensive Care, Uppsala University, SE-751 85 Uppsala, Sweden \\ ${ }^{\mathrm{b}}$ Department of Intensive Care, University Hospital, Uppsala, Sweden
}

\section{A R T I C L E I N F O}

\section{Article history:}

Received 24 September 2020

Revised 22 June 2021

Accepted 30 June 2021

\section{Keywords:}

Collaboration

Intensive care

Patient safety

Reflection

Work environment

Workload

\begin{abstract}
A B S T R A C T
Objectives: To describe the results of use of structured daily reflection assessments among healthcare workers at an intensive care unit over the course of one year.

Methods: In this descriptive retrospective study, data were analysed both quantitatively and qualitatively. The data encompassed 1095 work shifts, evaluated by healthcare workers at an intensive care unit using a structured daily reflection instrument. The areas evaluated were patient safety, workload and work environment, and free-text comments were possible.

Findings: The results showed that $36 \%(\mathrm{n}=395)$ of work shifts, most of them daytime shifts (44\%; $\mathrm{n}=161$ ), were affected. Workload was the area that affected most work shifts $(29 \% ; n=309)$. Missed nursing care, complex care and inaccurate communication impacted patient safety, while patient care, multitasking and working conditions affected workload. Work environment was impacted by organisational factors, environment, lack of control and moral stress.

Conclusion: Using daily reflection among healthcare workers in the intensive care unit illuminated areas that affect patient safety, workload, and work environment. The importance of communication and collaboration and how they can impact patient safety, workload, and the work environment were highlighted by the team.

๑ 2021 The Authors. Published by Elsevier Ltd. This is an open access article under the CC BY license (http://
\end{abstract} creativecommons.org/licenses/by/4.0/).

\section{Implications for clinical practice}

- Daily reflection by healthcare workers has a place in intensive care units to highlight factors, which can affect patient safety, workload, and work environment.

- Communication and collaboration can be seen either as risk factors or a factor of success regarding patient safety, workload, and work environment and imply the importance of interprofessional meetings regularly to effective management and maintain good routines and resolve misunderstandings early.

- In the complex environment of critical care, a reflection assessment tool can help healthcare workers describe emotionally, job, and situation level aspects of intensive care.

- Daily reflection can be an opportunity for healthcare workers to learn from, also when a work shift worked well.

\footnotetext{
* Corresponding author at: Department of Surgical Sciences, Anaesthesiology \& Intensive Care, Uppsala University, SE-751 85 Uppsala, Sweden.

E-mail address: ing-marie.larsson@surgsci.uu.se (I.-M. Larsson).
} 


\section{Introduction}

The work environment at an intensive care unit (ICU) is complex and technology-intense, and patients cared for at an ICU are seriously ill and unstable (Marshall et al., 2017). This leads to high physical, cognitive and emotional demands on ICU healthcare workers. Work-related stress is found among many ICU healthcare workers and originates from a range of sources (Pastores et al., 2019). The reported incidence of work-related stress among ICU healthcare workers is $>50 \%$ (Moss et al., 2016; Poncet et al., 2007). Factors thought to cause work-related stress among ICU nurses are lack of communication between nurses, physicians and assistant nurses, poor supervision, high demands and ethical, moral and mental stress (Moss et al., 2016; Pastores et al., 2019; Poncet et al., 2007; Trousselard et al., 2016). Additional causes of work-related stress are a physical work environment with advanced technology and non-ergonomic solutions (Bellagamba et al., 2015). Work-related stress can be prevented by changing the work environment, for example by ensuring adequate staffing in relation to workload (Moss et al., 2016; Ulrich et al., 2019) and offering communication training, reflection time and structured communication (Moss et al., 2016). Patient safety, quality of care and collaboration may be affected by workload and work environment, as there is a connection between staffing, skills and adverse events (The National Board of Health and Welfare, 2018; Ulrich et al., 2019). There is a risk of patients being exposed to adverse events in the ICU, with missed nursing care being one of several potential causes thereof (Bragadóttir et al., 2017; Tubbs-Cooley et al., 2017).

To our knowledge, no previous study has systematically described ICU healthcare workers' evaluation of patient safety, workload and work environment over an extended period of time.

The present study aimed to describe the results of a structured daily reflection assessment (DRA) completed by ICU healthcare workers over a period of one year.

\section{Method}

\section{Design}

Retrospective and descriptive study with quantitative and qualitative data.

\section{Participants}

Healthcare workers at a general ICU in Sweden, including intensive care nurses, assistant nurses and physicians (intensivists). After every work shift, 12-20 healthcare workers assessed the work shift using a structured DRA.

\section{Data collection}

The data consisted of evaluations made using an assessment tool, the DRA, over the course of one year; 2018. A similar tool had previously been used at two other hospitals in Sweden, but the DRA was developed into its current form at the present unit. The DRA had been used since December 2016 at the unit and was modified to its current form during 2017, but had not been validated. To complete the DRA, healthcare workers evaluated the work shift with regard to three areas: patient safety, workload and the work environment. The DRA includes a traffic light system to assist healthcare workers in evaluating each area. Green indicates an optimal work shift, yellow a strained work shift and red a very strained work shift (Table 1). After each daytime weekday shift, healthcare workers who have been working together in a patient room jointly evaluate and communicate how they have experienced the work shift. On evening, night and weekend shifts, the nurses and assistant nurses in a patient room jointly evaluate their work shift and the physicians in charge make their own evaluation of the on-call shift. If one or more of the team members consider an area to have been yellow or red during the work shift, the highest level is noted. If yellow or red is noted, a free-text comment is supposed to be added to explain why this level was chosen. If a work shift is evaluated as green, the team is supposed to discuss what made the shift green, but is not asked to add a freetext comment. The DRAs were completed on paper and given to a secretary who compiled the answers in an Excel file. Before the data were compiled, any free-text comments that could be connected to an individual or that might be offensive were reformulated by the manager in charge at the unit. The manager was therefore required to access the Excel file. The work shift assessment could only be connected to a patient room, not to any individual patient or staff.

Data on work shift characteristics, including the number of healthcare workers working, were collected from the unit's staff planning and intensive care data for intensive care cases enrolled during 2018 were collected from a national quality register for intensive care (SIR (The Swedish Intensive Care Registry), 2020a).

\section{Data analysis}

Quantitative data were recorded and then examined statistically using SPSS (version 26). Descriptive statistics were used to present variables from the DRA, Burden of Care Classification Sweden 2014 (VTS2014) and work shift characteristics. Two (2) work shifts out of 1095 were missing registrations. Imputation was performed in both cases and they were estimated as green based on the levels of the DRAs for the preceding and following work shifts.

Free-text comments were analysed in relation to the three DRA areas: patient safety, workload and work environment. Written comments from green work shifts were analysed separately. The free-text comments ranged in length, from longer explanations consisting up to 14 sentences to just a few words. Content analysis was applied at a manifest level, using an inductive approach that included an open coding, creating categories and abstraction (Elo and Kyngäs, 2008). The comments were read several times to gain an overall sense of the material. During this part of the coding process, notes and headings were written in the text. This step was repeated several times to describe all aspects of the contents. Thereafter, the comments were condensed and coded, with account taken of the research question and the aim of the study. Similar codes were grouped together and abstracted into categories. See examples in supplementary data Table 1. Lastly, the categories were divided across the three areas in the DRA and work shifts evaluated as green was divided separately.

\section{Rigour}

To ensure rigour, interrater reliability was assessed by identifying categories in the three DRA areas. The entire process was carried out individually by the first and last author, who have training in qualitative methodology. The researchers then met to discuss the findings and to reach consensus. All authors were familiar with the DRA and the context, which might have affected the interpretation of the written comments. Therefore, the material was discussed and re-read during the process to avoid internal validity bias and to improve trustworthiness. 
Table 1

Assessment tool, daily reflection assessment (DRA).

\begin{tabular}{|c|c|c|c|}
\hline & Green & Yellow & Red \\
\hline Patient safety & $\begin{array}{l}\text { Time for rounds, follow up and carry out plans, } \\
\text { e.g., handling medications including use-by } \\
\text { dates, check medical-technical equipment and } \\
\text { daily bandaging. Work according to medical } \\
\text { hygiene standards }\end{array}$ & $\begin{array}{l}\text { Patient safety is affected. Haven't had time } \\
\text { for rounds, follow up and carry out plans, e.g., } \\
\text { handling medications including use-by dates, } \\
\text { check medical-technical equipment and daily } \\
\text { bandaging. Have been forced to lower } \\
\text { priority of certain actions }\end{array}$ & $\begin{array}{l}\text { Haven't had time for any of rounds, follow up } \\
\text { and carry out plans, e.g., handling } \\
\text { medications including use-by dates, check } \\
\text { medical-technical equipment and daily } \\
\text { bandaging. Handling medications has been } \\
\text { affected because it's been confusing, stressful } \\
\text { and hard to focus. A lot of prescriptions } \\
\text { during a short period. Haven't had time to } \\
\text { write referrals and consult specialists. Hard } \\
\text { to find the time }\end{array}$ \\
\hline Workload & $\begin{array}{l}\text { Evaluation based on having time for all tasks } \\
\text { and a staffing/workload balance. E.g., } \\
\text { mobilisation and information for patients/ } \\
\text { relatives }\end{array}$ & $\begin{array}{l}\text { Finding time for all tasks is difficult. Have to } \\
\text { reprioritize during parts of my shift related to } \\
\text { workload }\end{array}$ & $\begin{array}{l}\text { There's not enough time for work tasks. The } \\
\text { entire shift has been reprioritizing }\end{array}$ \\
\hline Work environment & $\begin{array}{l}\text { Good communication. Clear prescriptions. } \\
\text { Optimal presences of all healthcare workers } \\
\text { e.g., physician, intensive care nurse and } \\
\text { assistant nurse. Good atmosphere. Good } \\
\text { workflow }\end{array}$ & $\begin{array}{l}\text { Poor communication in the team. Unclear } \\
\text { messages. Inadequate presence of all } \\
\text { healthcare workers e.g., physician, intensive } \\
\text { care nurse and assistant nurse despite the } \\
\text { need. Delayed breaks. Physician tasks left to } \\
\text { on-call docs, increasing their workload. } \\
\text { Generally pretty confusing }\end{array}$ & $\begin{array}{l}\text { Staff have to work overtime. Physician tasks } \\
\text { have to be left to on-call docs. Hardly anyone } \\
\text { has had a break or eaten. Very poor } \\
\text { communication and feedback. Bad } \\
\text { atmosphere. Poor safety. Lack of clarity }\end{array}$ \\
\hline
\end{tabular}

\section{Ethical consideration}

The study was reviewed by the Swedish Ethical Review Authority (Reg. no. 2019-06118). The study did not involve any processing of sensitive personal data.

\section{Findings}

Data were collected following every work shift in 2018, i.e., three times a day, at one ICU. The total sample consisted of 1095 DRA assessments. The ICU had eight beds; ICU characteristics from 2018 are shown in Table 2.

The green level was most common $(64 \%, n=700)$ for all areas in the DRA. The area most often assessed as yellow or red was workload, $25 \%(n=269)$ and $4 \%(n=40)$, respectively. The area most seldom assessed as yellow or red was patient safety, $12 \%(n=133)$ and $2 \%(n=24)$, respectively (Fig. 1$)$.

Yellow and red ratings were most common for daytime shifts $(\mathrm{n}=365), 37 \%(\mathrm{n}=135)$ and $7 \%(\mathrm{n}=26)$, respectively. Regardless of time of work shift, workload was the area most often assessed as yellow or red (Fig. 2).

The free-text comments in the DRAs explained why the ICU healthcare workers assessed a work shift as yellow or red. The findings from the free-text comments are presented in relation to the three DRA areas. A total of 10 categories was generated. Green work shift assessments were in some cases explained in free-text comments by the healthcare workers. These comments generated three categories, which are described separately (Fig. 3).

\section{Patient safety}

Three categories were identified that affected patient safety: missed nursing care, conflicting and inaccurate communication and complex care.

Missed nursing care or the risk of missed nursing care could involve insufficient monitoring and observation of patients or failure to carry out ambulation and mobilisation. There were also some cases of lack of completeness of patient care. The category conflicting and inaccurate communication referred to a lack of care prescriptions for patients' medication as well as inadequate care planning and information about arrival/discharge of patients to/ from the ICU. Complex care comprised caring for an unstable
Table 2

Characteristics for the ICU during 2018.

\begin{tabular}{ll} 
Number of healthcare workers & \\
Intensive care nurse-to-patient ratio (all work shifts) & $0.6: 1$ \\
Assistant nurse-to-patient ratio (all work shifts) & $0.7: 1$ \\
Intensivist physician-to-patient ratio (daytime work shifts) & $0.5: 1$ \\
ICU admissions (number) & 993 \\
New admissions a day (mean) & 2.7 \\
ICU care days (number) & 2075 \\
ICU Length of stay, days per patient (mean) & 2.09 \\
Invasive ventilation & 667 \\
Episodes (number) & 1160 \\
Invasive ventilation days (number) & \\
Continuous renal replacement therapy (CRRT) & 89 \\
Episodes (number) & 271 \\
CRRT days (number) & \\
Intrahospital transports & 781 \\
Episodes (number) & 2.1 \\
\hline Intrahospital transports a day (mean number) & \\
\hline
\end{tabular}

ICU; intensive care unit, CRRT; continuous renal replacement therapy.

patient in an environment outside the ICU, for example in the Xray department, or performing surgery in the ICU. Uncertainty regarding medical devices in patient care was also an important aspect of this category.

\section{Workload}

Factors that affected workload were identified in three categories: patient care, multitasking care and working conditions. The category patient care included aspects related to patients requiring complex bedside care and extensive contact with relatives. Workload was also affected by multitasking care, meaning that healthcare workers performed parallel care actions with several ICU patients, for example being simultaneously responsible for admitting one patient and discharging another. Working conditions encompassed work-related aspects of distribution of responsibilities, for instance for various administrative tasks and inexperienced healthcare workers. 


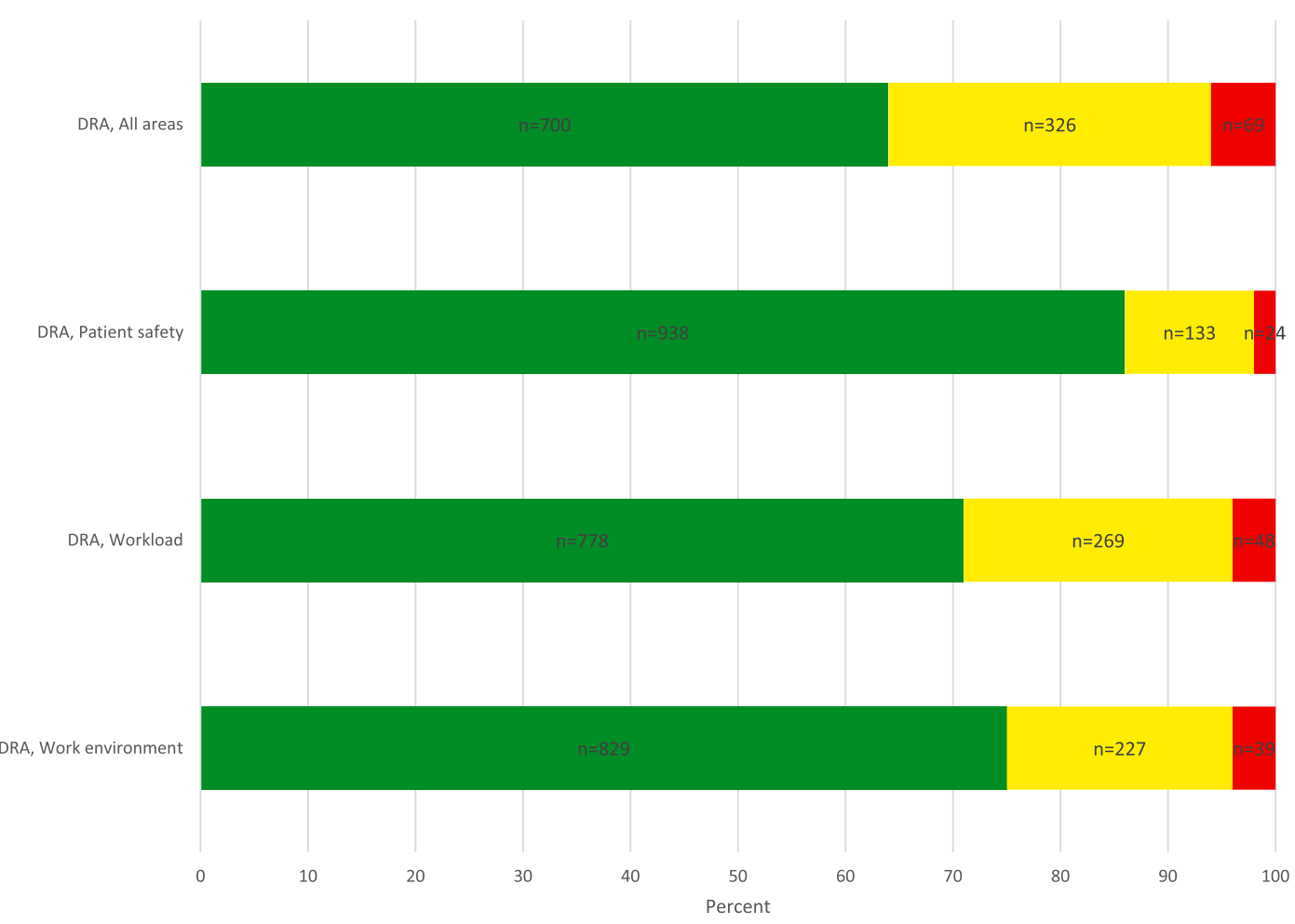

Fig. 1. Distribution of daily reflection assessment (DRA).

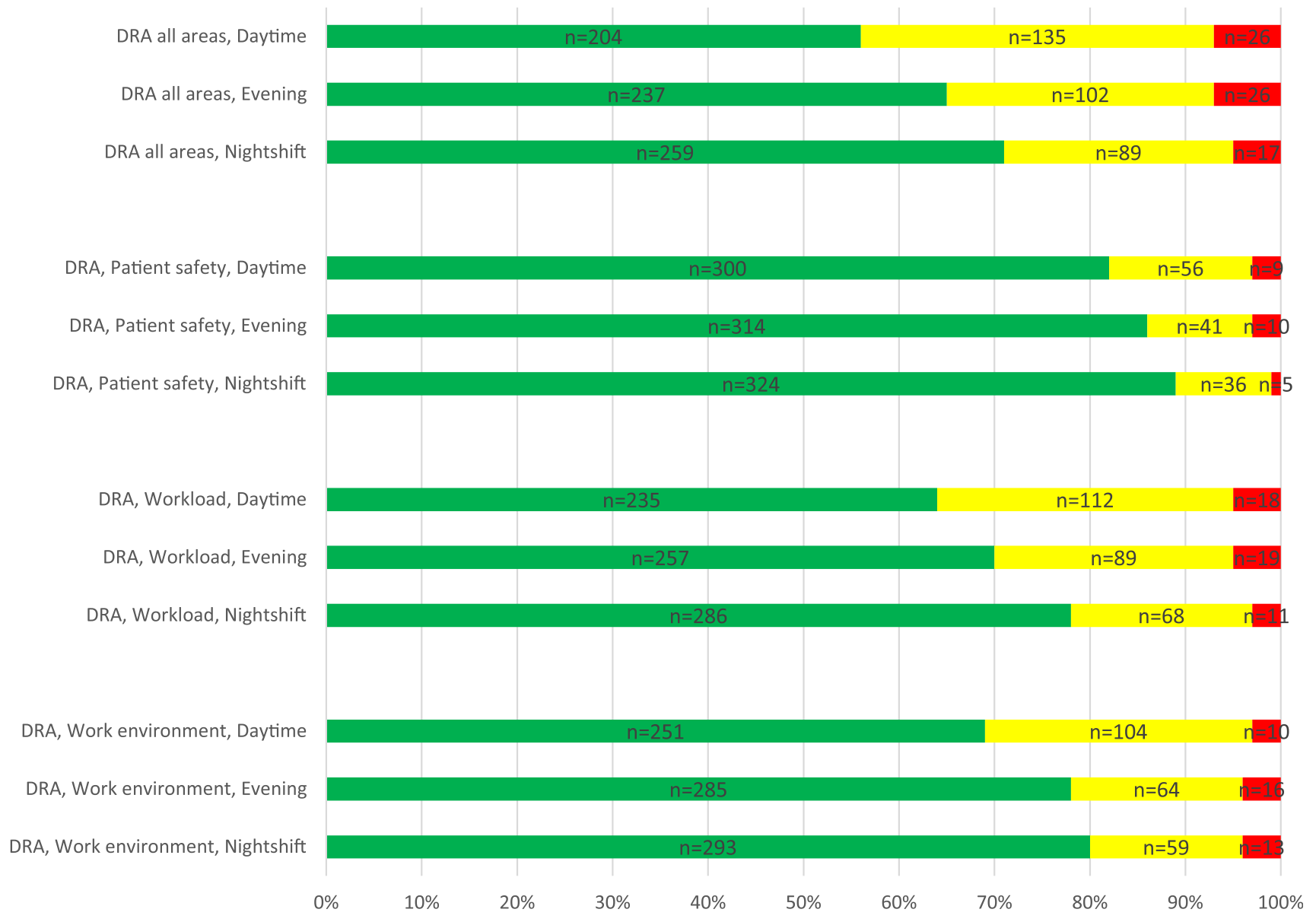

Fig. 2. Distribution of daily reflection assessment (DRA) presented by work shift. 


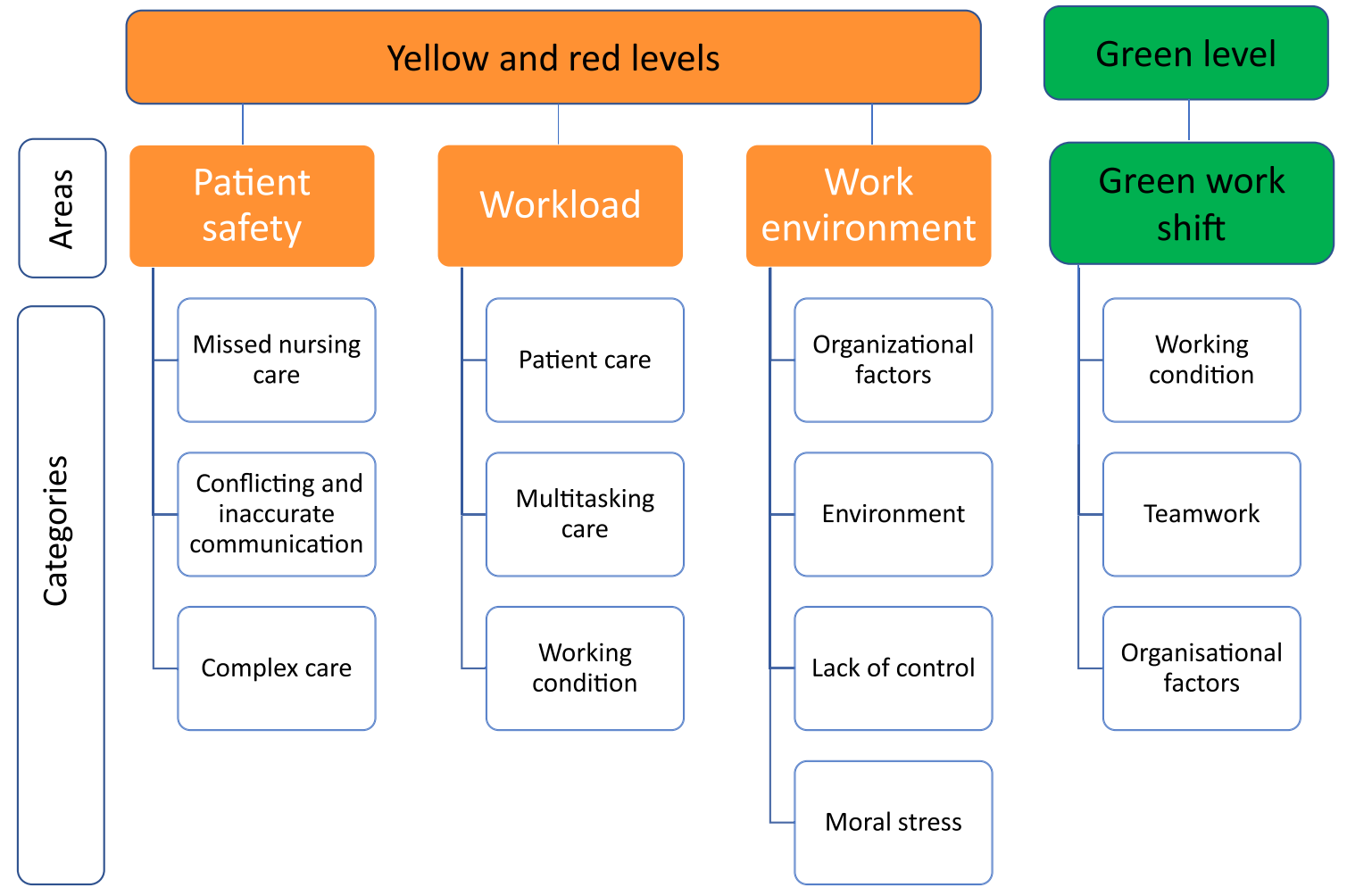

Fig. 3. Illustration of categories derived from free-text comments in the daily reflection assessment (DRA).

\section{Work environment}

Four categories were identified that impacted the work environment: organisational factors, environment, lack of control and moral stress. Poor planning could mean that healthcare worker staffing was insufficient in relation to patients and care demands, which in turn resulted in missed breaks and overtime. These factors are included in the category organisational factors. The category environment refers mainly to noise levels caused by both medical equipment and conversations between healthcare workers in the patient room. Lack of control relates to inadequate collaboration between healthcare workers as well as unstructured work and planning due to lack of communication. There could also be moral stress in the form of a feeling of inadequacy in patient care and in contact with a patient's family.

\section{Green work shifts}

The healthcare teams were not asked to add free-text comments if a work shift was evaluated as green. However, teams chose to write comments for $30 \%(n=212)$ of green work shifts. When the healthcare workers described a work shift as green, all areas assessed in the DRA were considered to be balanced. Three categories were identified: working conditions, teamwork and organisational factors. The focus in working conditions was on collaboration and communication among the healthcare workers, that all worked well and tasks were performed in a timely manner. A work shift was also green when teamwork was optimal, meaning that the healthcare workers received help from colleagues if needed. The third category, organisational factors, was affected by staffing and the presence of all staff categories in relation to patient occupancy, meaning that the care burden was appropriate.

\section{Discussion}

This study explored healthcare workers' evaluations of their work shifts. Evaluation was performed using a structured daily reflection instrument, the DRA, with free-text comments explaining the assessments made. Our main findings showed that work shifts assessed as yellow or red, were most common in the daytime, with the areas workload and work environment most often being strained. Missed nursing care, complex care and inaccurate communication affected patient safety, while patient care, multitasking care and working conditions affected workload. Lack of control and moral stress were important aspects that affected the work environment.

That daytime shifts were more often yellow or red was surprising, as more healthcare workers are on duty during day shifts than during evening, night and weekend shifts, including the manager, a secretary and other professionals who can help if needed. During evening, night and weekend shifts, there is also a limited number of intensivists available. It should be noted that patient safety was often assessed as green, even when workload and work environment were assessed as strained. Explanations for this did not emerge in the free-text comments in the DRA. One reason may be that healthcare workers accepted missing their breaks if this meant maintaining patient safety.

The findings from the free-text comments revealed additional factors that could affect patient safety, workload and work environment. Communication and collaboration were frequently mentioned, both occurring in and affecting all DRA areas. Previous studies have shown that if communication and collaboration are efficient, this can decrease stress and burnout among ICU healthcare workers (Moss et al., 2016; Ulrich et al., 2019). If communication and collaboration between healthcare workers function, this may also strengthen critical care nurses' autonomy and control 
over specific nursing practices, thereby increasing their contributions to clinical decision-making and their input to unit-level decisions and organisation (Papathanassoglou et al., 2012).

In the present study, the responses to the DRAs illustrated the multifaceted, demanding and technology-intense care that healthcare workers must manage during work shifts at the ICU (Marshall et al., 2017; SIR (The Swedish Intensive Care Registry), 2020b). Patient care, one of the categories affecting workload, encompassed several aspects and might correspond to direct and indirect patient care, as previously described elsewhere (Abbey et al., 2012; Douglas et al., 2013; Pelletier and Duffield, 2003). The reason that patient care had a large impact on workload in the DRA may be that critical care nurses spent $52 \%$ of their time in direct patient care (Douglas et al., 2013). The DRA category multitasking care is similar to cognitive workload; if there is an imbalance in cognitive workload, it may affect healthcare workers' attentiveness and ability to identify and assess patient needs, potentially leading to errors in patient care (Carayon and Alvarado, 2007). In the present study, the categories multitasking care and working conditions in the area of workload had contents similar to what has been described as the job and situation levels within the framework of nursing workload (Carayon and Gürses, 2005). The complex environment of the ICU often stimulates ICU healthcare workers, but when they lose control over their working situation, the workload is experienced negatively and the risk of developing work-related stress and burnout increases (Bellagamba et al., 2015; Moss et al., 2016; Pastores et al., 2019).

Loss of control over the working situation may have been caused by the structure of the ICU, where there were an average of 2.7 new admissions/day and eight (8) patient beds. This meant that a healthcare worker could be responsible for admitting one patient and discharging another at the same time. Furthermore, this meant that the ICU nurse-to-patient ratio was affected, which may explain feelings of loss of control, and may affect patient safety. This is something managers should take into account, for example by ensuring appropriate staffing and routines.

Increased workload may also affect patient safety. This was illustrated in the present study by the categories missed nursing care, conflicting and inaccurate communication and complex care. Previous research has shown that missed nursing care decreases when the teamwork among healthcare workers is functional and when staffing is adequate in relation to the nursing workload (Bragadóttir et al., 2017; Chapman et al., 2017; Kalisch and Xie, 2014). An association between workload and missed nursing care has also been found among nurses working in a neonatal intensive care unit (Tubbs-Cooley et al., 2019). The relationship between workload and patient safety involves factors such as equipment and patient-related or human error (Carayon and Alvarado, 2007). All these three causes were represented in the three categories of patient safety in the present study. Several of the aspects that we described as affecting workload were recently described as turbulence (Browne and Braden, 2020). Turbulence is an interesting concept and should be considered in any future validation of the DRA.

In this study, the free-text responses often included comments on missed nursing care, despite the fact that patient safety was often evaluated as green in the DRA. This was unexpected and may be because the practice of nursing is still seen as secondary to medical activities.

The third DRA area, work environment, and its associated categories, described ICU-related aspects that healthcare workers could not influence, such as sufficient staffing and environmental factors. However, these aspects may increase feelings of moral stress among healthcare workers. In the present study, the healthcare workers expressed moral stress mainly in relation to the organisation's barriers to nursing, such as inadequate time to care for patients and feelings of overwhelming demands in the ICU environment. These descriptions are close to the meaning of moral stress as previously described among ICU healthcare workers (Dodek et al., 2016; McAndrew et al., 2018; Papathanassoglou et al., 2012).

The DRA instructions asked the healthcare workers to write comments if a work shift was evaluated as yellow or red, but comments were also given when all of the healthcare workers had evaluated the work shift as green, i.e., optimal. These comments described what caused a work shift to be in balance, such as the possibility to reach the green level even with a high workload when workers received help from colleagues. This might be interpreted as an indication that healthcare workers wanted to show that they were in control, but also wanted confirmation of their situation and support even if they evaluated a work shift as green. The Job-Demand-Control-Support model for healthy work conditions shows that workers who are subject to high demands in combination with little control and little support run the greatest risk of suffering from work-related stress (Karasek and Theorell, 1990), which might be avoided through follow-ups of the DRA.

The factors identified through the DRAs as affecting patient safety, workload and work environment among healthcare workers in an ICU are known from previously mentioned studies, but are there mainly described separately. In the DRA, all three areas, i.e., patient safety, workload and work environment, are captured; to our knowledge there is no other assessment in use that includes all three areas. Furthermore, the DRA provides a simple way for healthcare workers to reflect on their work shift. Conducting a structured assessment of patient safety, workload and the work environment after each work shift within a team enables the team to evaluate their work shift and responsible managers to see which areas need development and improvements. The DRA may also help ICU healthcare workers to process their work shift within the team, including both positive and negative events. Whether use of the DRA can reduce ICU healthcare workers' feelings of stress needs to be further investigated. The number of comments analysed in the DRAs increases the reliability of the findings, but further validation is needed.

The outbreak of COVID-19 has rapidly changed the working situations in ICUs, resulting in increased workload, including physical and mental challenges for healthcare workers (Maben and Bridges, 2020; Walton et al., 2020). During the COVID-19 pandemic, the importance of reflection has been illuminated. The DRA might serve as a tool for managing the exceptional working situation.

\section{Limitations}

This study has some limitations. The study was performed at a single ICU, which might be a limitation to transferability. Most of the DRA evaluations were performed by ICU nurses and assistant nurses, without participation from the intensivists at the unit. This means that the results are only valid for these professions, not for all healthcare workers. Still, the results reflected most of the healthcare workers' daily reflections on patient safety, workload and the work environment over a period of one year at an ICU. The healthcare workers' assessments and comments in the DRA have clarified what causes a work shift in an ICU to be considered optimal or strained. However, the DRA does not show changes to the healthcare workers' stress levels during shifts. Furthermore, the DRA does not show the healthcare workers' opinions of the DRA, for example if they can discuss things honestly with each other. This needs to be further studied. How the DRA affected healthcare workers' job satisfaction, stress or well-being was not evaluated in the present study, which can be seen as a limitation. The DRA has not been validated, which is also a limitation. 
This study did not comply with data of seniority or level of staff experiences. Therefore, it should be taken into account when interpreting data and further studies and validating the DRA. However, the overall results may be generating hypotheses for future studies.

\section{Conclusion}

Using a simple reflection assessment daily reveals valuable information from ICU healthcare workers. This study illustrated several areas that were affected regarding patient safety, workload, and work environment. The intensive care unit team highlighted the importance of communication and collaboration and how they can impact patient safety, workload, and the work environment. The information from DRA can be valuable for healthcare workers at an ICU as for the organisation and be used in ICUs to analyse and capture information to make improvements.

\section{Ethical statement}

The study was reviewed by the Swedish Ethical Review Authority (Reg. no. 2019-06118). The study did not involve any processing of sensitive personal data.

\section{Funding Source}

None.

\section{Declaration of Competing Interest}

The authors declare that they have no known competing financial interests or personal relationships that could have appeared to influence the work reported in this paper.

\section{Acknowledgements}

The authors wish to thank the participating ICU healthcare workers for their valuable input on the Daily reflection assessment instrument. Our thanks are also extended to former ICU manager Ms Marie Thorén for developing and introducing the DRA in its current form.

\section{References}

Abbey, M., Chaboyer, W., Mitchell, M., 2012. Understanding the work of intensive care nurses: A time and motion study. Aust. Crit. Care 25, 13-22. https://doi. org/10.1016/j.aucc.2011.08.002.

Bellagamba, G., Gionta, G., Senergue, J., Bèque, C., Lehucher-Michel, M.P., 2015. Organizational factors impacting job strain and mental quality of life in emergency and critical care units. Int. J. Occup. Med. Environ. Health 28, 357367. https://doi.org/10.13075/ijomeh.1896.00121.

Bragadóttir, H., Kalisch, B.J., Tryggvadóttir, G.B., 2017. Correlates and predictors of missed nursing care in hospitals. J. Clin. Nurs. 26, 1524-1534. https://doi.org/ 10.1111/jocn.13449.

Browne, J., Braden, C.J., 2020. Nursing turbulence in critical care: Relationships with nursing workload and patient safety. Am. J. Crit. Care. https://doi.org/10.4037/ ajcc2020180.

Carayon, P., Alvarado, C.J., 2007. Workload and patient safety among critical care nurses. Crit. Care Nurs. Clin. North Am. https://doi.org/10.1016/j. ccell.2007.02.001.
Carayon, P., Gürses, A.P., 2005. A human factors engineering conceptual framework of nursing workload and patient safety in intensive care units. Intensive Crit. Care Nurs. 21, 284-301. https://doi.org/10.1016/j.iccn.2004.12.003.

Chapman, R., Rahman, A., Courtney, M., Chalmers, C., 2017. Impact of teamwork on missed care in four Australian hospitals. J. Clin. Nurs. 26, 170-181. https://doi. org/10.1111/jocn.13433.

Dodek, P.M., Wong, H., Norena, M., Ayas, N., Reynolds, S.C., Keenan, S.P., Hamric, A., Rodney, P., Stewart, M., Alden, L., 2016. Moral distress in intensive care unit professionals is associated with profession, age, and years of experience. J. Crit. Care. 31, 178-182. https://doi.org/10.1016/j.jcrc.2015.10.011.

Douglas, S., Cartmill, R., Brown, R., Hoonakker, P., Slagle, J., Schultz Van Roy, K., Walker, J.M., Weinger, M., Wetterneck, T., Carayon, P., 2013. The work of adult and pediatric intensive care unit nurses. Nurs. Res. https://doi.org/10.1097/ NNR.0b013e318270714b.

Elo, S., Kyngäs, H., 2008. The qualitative content analysis process. J. Adv. Nurs. 62 , 107-115. https://doi.org/10.1111/j.1365-2648.2007.04569.x.

Kalisch, B.J., Xie, B., 2014. Errors of omission: missed nursing care. West. J. Nurs. Res. 36, 875-890. https://doi.org/10.1177/0193945914531859.

Karasek, R., Theorell, T., 1990. Healthy Work-Stress, Productivity and the Reconstruction of Working Life. Basic Books, New York.

Maben, J., Bridges, J., 2020. Covid-19: Supporting nurses' psychological and mental health. J. Clin. Nurs. 29, 2742-2750. https://doi.org/10.1111/jocn.15307.

Marshall, J.C., Bosco, L., Adhikari, N.K., Connolly, B., Diaz, J.V., Dorman, T., Fowler, R. A., Meyfroidt, G., Nakagawa, S., Pelosi, P., Vincent, J.-L., Vollman, K., Zimmerman, J., 2017. What is an intensive care unit? A report of the task force of the World Federation of Societies of Intensive and Critical Care Medicine. J. Crit. Care 37, 270-276. https://doi.org/10.1016/j.jcrc.2016.07.015.

McAndrew, N.S., Leske, J., Schroeter, K., 2018. Moral distress in critical care nursing: The state of the science. Nurs. Ethics. https://doi.org/10.1177/ 0969733016664975.

Moss, M., Good, V.S., Gozal, D., Kleinpell, R., Sessler, C.N., 2016. An official critical care societies collaborative statement: Burnout syndrome in critical care healthcare professionals: A call for action. Crit. Care Med. 44, 1414-1421. https://doi.org/10.1097/CCM.0000000000001885.

Papathanassoglou, E.D.E., Karanikola, M.N.K., Kalafati, M., Giannakopoulou, M., Lemonidou, C., Albarran, J.W., 2012. Professional autonomy, collaboration with physicians, and moral distress among European intensive care nurses. Am. J. Crit. Care 21, e41-e52. https://doi.org/10.4037/ajcc2012205.

Pastores, S.M., Kvetan, V., Coopersmith, C.M., Farmer, J.C., Sessler, C., Christman, J. W., D’Agostino, R., Diaz-Gomez, J., Gregg, S.R., Khan, R.A., Kapu, A.N., Masur, H., Mehta, G., Moore, J., Oropello, J.M., Price, K., 2019. Workforce, workload, and burnout among intensivists and advanced practice providers: A narrative review. Crit. Care Med. 47, 550-557. https://doi.org/10.1097/ CCM.0000000000003637.

Pelletier, D., Duffield, C., 2003. Work sampling: Valuable methodology to define nursing practice patterns. Nurs. Heal. Sci. https://doi.org/10.1046/j.14422018.2003.00132.x.

Poncet, M.C., Toullic, P., Papazian, L., Kentish-Barnes, N., Timsit, J.-F., Pochard, F. Chevret, S., Schlemmer, B., Azoulay, É., 2007. Burnout syndrome in critical care nursing staff. Am. J. Respir. Crit. Care Med. 175, 698-704. https://doi.org/ 10.1164/rccm.200606-8060C.

SIR (The Swedish Intensive Care Registry), 2020a. https://www.icuregswe.org/dataresultat/utdataportalen/ [WWW Document].

SIR (The Swedish Intensive Care Registry), 2020b. http://www.icuregswe.org/ [WWW Document].

The National Board of Health and Welfare, 2018. Kompetensförsörjning och patientsäkerhet Hur brister $\mathrm{i}$ bemanning och kompetens påverkar patientsäkerheten.

Trousselard, M., Dutheil, F., Naughton, G., Cosserant, S., Amadon, S., Dualé, C., Schoeffler, P., 2016. Stress among nurses working in emergency, anesthesiology, and intensive care units depends on qualification: a Job Demand-Control survey. Int. Arch. Occup. Environ. Health 89, 221-229. https://doi.org/10.1007/ s00420-015-1065-7.

Tubbs-Cooley, H.L., Mara, C.A., Carle, A.C., Mark, B.A., Pickler, R.H., 2019. Association of nurse workload with missed nursing care in the neonatal intensive care unit. JAMA Pediatr 173, 44. https://doi.org/10.1001/jamapediatrics.2018.3619.

Tubbs-Cooley, H.L., Pickler, R.H., Mara, C.A., Othman, M., Kovacs, A., Mark, B.A., 2017. Hospital Magnet ${ }^{\circledR}$ designation and missed nursing care in neonatal intensive care units. J. Pediatr. Nurs. 34, 5-9. https://doi.org/10.1016/j.pedn.2016.12.004.

Ulrich, B., Barden, C., Cassidy, L., Varn-Davis, N., 2019. Critical care nurse work environments 2018: Findings and implications. Crit. Care Nurse 39, 67-84. https://doi.org/10.4037/CCN2019605.

Walton, M., Murray, E., Christian, M.D., 2020. Mental health care for medical staff and affiliated healthcare workers during the COVID-19 pandemic. Eur. Hear. J. Acute Cardiovasc. Care. https://doi.org/10.1177/2048872620922795. 